\title{
The Role of Local Community in the Implementation of Ethiopian Tourism Development Policy: The Case of Harari People Regional State, Ethiopia
}

\author{
Mesay Derar and Mohammednur Ahmed, $\mathrm{PhD}$
}

\begin{abstract}
The main objective of the study is to assess the role of local community in implementing the Ethiopian tourism development policy in Harari people regional state, Harar city. To achieve the research objective data was collected from randomly selected residents that involve in filling the questionnaire designed for the study. Interviews and observations were also carried out to support data collected using the questionnaire. Besides, the study employed concurrent mixed approached with the aim of triangulating quantitative by qualitative data. The finding of the study revealed that local communities have good awareness about their role in tourism policy implementation although the experts are complaining about its adequacy. Community participation is found to be also affected be participatory public administration, community awareness, and participation approach. Furthermore, during the tourism policy implementation limited of awareness, coordination and cooperation, trained professional as well as shortage of budget were mention among the challenges of policy implementation. From this it can be concluded that all stakeholders have to play their role in promoting local community participation in the region to reap the advantages of the policy.
\end{abstract}

Keywords: local community, Ethiopian tourism development policy, implementation, role

DOI: $10.7176 /$ PPAR/12-1-01

Publication date: January $31^{\text {st }} 2022$

\section{Introduction}

Tourism industry is among the fast-growing businesses of the global economy with greater potential contribution to national development. Tourism plays an important role by serving as a source of income, foreign exchange and employment opportunities (Baumand Weinz, 2010). According to Christie et al (2014) in Sub-Saharan Africa by the year 2011 tourism directly contributed 2.7\% to GDP and 5.3 million direct tourism jobs which are projected to increase to 6.8 million by 2022 . In the year 2016 , the tourism sector has a $10.2 \%$ direct contribution to global GDP with projected increase of $3.6 \%$ annually. Besides, it constitutes $3.6 \%$ of total employment of the globe in 2016 (WTO, 2017). Recently, in many developing counties tourism is becoming an increasingly relevant economic sector. Besides, Getahun (2011) pointed out, referring to World Economic Forum competitiveness study on tourism and travel, that most new jobs in developing countries are going to be generated by the tourism industry. Despite the fact that tourism has an important contribution to the economic development of one nation, it threatens the socio-cultural and environmental sustainability of a society, especially in developing countries. Therefore, this needs a policy in relation to tourism development in order to minimize and manage the adverse effect of the tourism industry on the environment, culture, society and maximize the economic benefit for the society at large (Zaei and Zaei, 2013).

One of the main reasons that governments formulate and implement tourism policy throughout the world is to achieve positive results in economic, social and cultural development. In line with this, the Federal Democratic Republic of Ethiopia (FDRE) constitution under article 52/2/C provides the power to regional states to formulate and execute their own policies, strategies and plans of the State (FDRE, 1995). Tourism development policy of Ethiopia was formulated by Ministry of Culture and Tourism and adopted August 7 , 2009 ,by Council of Ministers at $92^{\text {nd }}$ regular session meeting for the first time in Ethiopia history. The policy was adopted with a vision to see Ethiopia's tourism development led responsibly and sustainably contributing its share to the development of the country by aligning itself with poverty reduction. As a result, the ministry of culture and tourism has identified key stakeholders and pointed out their role for policy implementation; the stakeholders include government organizations, investors, civil society, the general public and the local community (MoCT, 2009). However, for developing countries like Ethiopia, the fundamental challenge is to realize inclusive effective policy formulation and implementation. Participation of various stakeholders is vital for implementing a policy which enhances partnership in coordinating different efforts and minimizing wastage of resources. Though tourism sector is growing from time to time, the roles and contribution of local communities in tourism development is observed to be limited in contrast with the tourism potentials.

Taking in to account the importance of local community in policy formulation and implementation, the government of Ethiopia designed the tourism development that paves the way for local community participation. This direction is expected to produce economic benefits to the community given the increasing number of tourists and making tourist stay convenient. In Ethiopia as Hayimanot (2017) pointed out on Ministry of Culture 
and Tourism Journal of culture and tourism by referring the ministry of culture and tourism report, in the first half of 2013-2014 the number of tourists increase to 36\%. Therefore, participating local community in implementing the tourism policy assumed to contribute to inclusive and sustainable economic development that benefits the community at the grass root. (Messele, 2010). In order to bring sustainable tourism development, to increase societal policy acceptance, and to effectively implement a policy; local communities should involve in tourism decision making, training and income generating activities (Bule, 2016). Though each regional states of Ethiopia have been granted the right to formulate and adopt policies based on the regional context they have been executing policies which are formulated and adopted at the federal level. Like the nine regional states and two administrative cities, Harari People Regional State has been executing the tourism development policy formulated by the federal government. Hence, the major aim of study was to assess the role of local community in the formulation and implementation national tourism development polices as well as identify factors affecting local community participation. Moreover, the paper attempts to answer two basic research questions.

1. What is the role of local communities in tourism development policy implementation?

2. What are the major factors that affect the participation of local community in the policy implementation process?

\section{Description of the Study Area}

Harari people regional state is located in the eastern part of Ethiopia surrounded by the Oromia Regional State at geographic coordination of 911' 49" - 924' 42" north latitude and 420' 03" 30 - 420' 16" 24" east longitude and $515 \mathrm{~km}$ to the south-east of Addis Ababa at 2200 meter elevation above sea level (Wehib,2015). The total area of the region is $343.2 \mathrm{sq}$. $\mathrm{km}$ (19.5 sq. km urban and $323.7 \mathrm{sq} . \mathrm{km}$. rural). According to the EFDRE population census commission (2008), the total population of the region is 183,415; 92,316 male and 91,099 female. The city has two distinct sections, which are the old and new city parts. The old city compasses the walled part which known as "Jugol" which is far more densely populated than others areas (Essays- UK, 2013). Administratively the historical the region is divided in to 9 woredas and 19 Kebeles (HPRS, 2016).

The Harar is a city which originates back to $13^{\text {th }}$ c,the traditional houses of the old city of "Jugol" which is built traditionally using stone and plaster with flat roof, the fortified walls with its gates and tower, exciting market-place, historical building like Arthur Rimbaud house which is named after the renowned French poet and the strategic location of the place which resulted the city to be a center for Islamic culture, commerce and the legacy of Islamic culture with more than 82 mosques and 102 shrines gave the city a name to be considered as fourth holy city of Islam and its refreshing cool air make the city exciting place to visit (Taffese,2016).Generally the historical city of Harar specifically "Jugol" the fortified city with its unique buildings, great encircling wall, and well-fashioned gates received international recognition in 2006 when they were registered by UNESCO as part of the world heritage site ,not only of the city and Ethiopia but of humanity as a whole and Harar city has been awarded the international peace prize by UNESCO in 2004 as a city of peace, tolerance, and solidarity in everyday life. ${ }^{l}$ The rationale behind choosing the study area is because the area is a tourist destination area which has a huge tourism potential which is registered by UNESCO as a world heritage site. In addition, the tourism activity in the area is largely interconnected with the local communities, as both the tourism destination areas and local peoples live harmoniously together at the same place. Therefore the study was undertaken on the local community of Harar specifically living in the tourist destination area of "Jugol".

\section{Objectives of the Study}

The general objective of the study was to assess the role of local community in the implementation of Ethiopian Tourism Development policy in Harari People Regional State (HPRS); the city state. The specific objectives of the study include:

1. To understand the local community awareness about the respective national policy

2. To investigate local community role in implementing tourism development policy

3. To identify factors affecting local community participation in tourism development policy implementation

4. To explore challenges tourism development policy implementation in the region.

\section{Research Methodology}

To address the research problem and to achieve the stated objectives, a cross-sectional survey was conducted in 2018. The aim of the survey was exploring and analyzing the role of local community in implementing the Ethiopian tourism development policy in Harari people Regional State, Harar city. Thus, the population of the study was households living in city. To come up with representative and relevant sample, both random sampling and non-random sampling technique were used in this research. However, among the total 19 kebelles (i.e.

${ }^{1}$ (http: // www. Africa guide.com/country/Ethiopia/) 
30,591 households), the study purposively selected the tourist attraction site of "Jugol" which consist of 7 kebelles (i.e. 6578 households). The sample size was determined using Raosoft (2004) ${ }^{1}$ sample size determination calculator. So, with a population size of 6578 , confidence level of $95 \%$, and response distribution of $85 \%$ and 0.05 margin error; the sample size of the study was $\mathbf{1 9 1}$ households. The distribution of sampled households is presented in the following table.

Table 1: The Distribution of the Participants in Questionnaire

\begin{tabular}{|l|l|l|l|l|}
\hline No & Name of Kebele & No of Household Head & Sample Size & Percent \\
\hline 1 & Kebele 1,7 & 1825 & 53 & 27.7 \\
\hline 2 & Kebele 5,6 & 1864 & 54 & 28.3 \\
\hline 3 & Kebele 2,3,4 & 2889 & 84 & 44 \\
\hline Total & 6578 & 191 & 100 \\
\hline
\end{tabular}

Generally, the survey covered 191 households to fill questionnaire and six respondents were interviewed such as government officials, tourism expert, guide, manager, and hotle owner. In selecting the households Cluster-multi-stage sampling was used. First, the seven (7) kebelles were divided into three (3) geographical clusters. Second, based on the number of households in the cluster, sample respondents were proportionally assigned. Finally, the researcher systematically selected the respondents from each cluster and kebelles to distribute the questionnaire. Moreover, Harari cultural, heritage and tourism bureau head and tourism expert, hotels manager, owner (Sheriff Museum), traditional guest house owner and tourist guide were purposively selected taking in to account their ability to provide relevant information to deal with the research objectives and questions. Moreover, to serve the aim of the study, both qualitative and quantitative data were used. The mixed approach design was used to concurrently complement the limitation both approaches. With regard to sources of data, primary and secondary sources were used.

In collecting the primary data, a questionnaire containing both closed and open-ended questions was distributed to sampled respondents in the three (3) clusters. The open-ended questions were designed to gather more opinions and ideas from the respondents. Besides, semi-structured interview and observation were conducted to gather qualitative data. Before questionnaires were distributed, the questionnaire which has been prepared in English was translated in to Amharic (i.e. local language) with the help of language expert. Interview was also another tool that was used to gather data from selected samples. Thus, semi-structured personal interviews were employed to get qualitative data in relation to the role of local community in tourism policy implementation. Further, observation method was employed and applied by using non- participant observation to observe different capacity building activities like training provided for local peoples by the Harari culture, heritage and tourism office in Enay Abida handicraft college, to observe different tourist accommodation and activities provides by local peoples and to observe different tourist attraction places which support other data gathering tools. The Secondary data were collected from previous research document, policy documents, government reports, books and journal articles.

Finally, the researchers employed both quantitative and qualitative data analysis procedures. For quantitative data also, the questionnaire was coded and analyzed by using the SPSS V20. The quantitative data were analyzed by using SPSS procedures like frequencies, percentage, mean and figure, table, test of independence, and correlation. Further, the analysis procedures for the qualitative data was through transcribing the voice data into text, polishing the data based on the objective of the study, coding, categorizing and analyzing. There was also an integration of the primary data with the secondary data.

Ethical consideration is essential at the time of data collection and interpretation. The researchers consider the relevance, usefulness of the research and kept in mind the objective of inquiry, why the information is required, and for what purpose it is needed. In addition, while collecting data, respondents were first asked their agreement to participate in the survey and their response was kept confidential. Finally, after the data is collected the researchers analyzed the data and reported the findings with utmost good faith.

\section{Discussion and Presentation}

\subsection{Demographic Characteristic of Respondents}

This part of the data analysis is designed to describe major demographic characteristics of respondents such as age, gender, marital status, education level, and number of years residing in the city. Descriptive statistics such as frequencies and percentages have been employed to discuss the demographic characteristics.

\footnotetext{
${ }^{1}$ (http://www.raosoft.com/samplesize.html).
} 
Table 2: Demographic Characteristic of Respondents

\begin{tabular}{|c|c|c|c|}
\hline \multicolumn{2}{|c|}{ Demographic Character } & Frequency & $\%$ \\
\hline \multirow[t]{3}{*}{ Sex } & Male & 111 & 58.1 \\
\hline & Female & 80 & 41.9 \\
\hline & Total & 191 & 100 \\
\hline \multirow[t]{4}{*}{ Age } & Below 30 & 118 & 61.8 \\
\hline & $30-55$ & 61 & 31.9 \\
\hline & Above 55 & 12 & 6.3 \\
\hline & Total & 191 & 100 \\
\hline \multirow[t]{5}{*}{ Educational Status } & Primary Education & 21 & 11 \\
\hline & Secondary Education & 42 & 22 \\
\hline & Collage/ University & 99 & 51.8 \\
\hline & No Formal Education & 29 & 15.2 \\
\hline & Total & 191 & 100 \\
\hline \multirow[t]{4}{*}{ Occupational Status } & Government Employee & 21 & 11 \\
\hline & Non-Government Employee & 46 & 24 \\
\hline & Unemployed & 124 & 65 \\
\hline & Total & 191 & 100 \\
\hline \multirow[t]{4}{*}{ Years of living in Harar } & Less than 10 years & 12 & 6.28 \\
\hline & Longer than 10 years & 38 & 20 \\
\hline & Since birth & 141 & 74 \\
\hline & Total & 191 & 100 \\
\hline
\end{tabular}

Source: Field Survey

The above table 2 presents the demographic characteristics of respondents. Out of the total respondents, 111 $(58.1 \%)$ were male and $80(41.9 \%)$ were female. With regard to age distribution, $61.8 \%$ of respondents are reported their age was below 30 years, while the remaining $31.9 \%$ and $6.3 \%$ fall in the $30-55$ (adult) and above 55 (elder) years of age categories respectively. This result gives the implication that most of the respondent households are headed by male. Concerning the educationalstatus, $51.8 \%$ of the respondents had completed college or university education, $22 \%$ had secondary education. Meanwhile, $15.2 \%$ and $11 \%$ of the respondents had no formal education and primary education respectively. It is also indicated in the table that of the respondents $(65 \%)$ were unemployed, $24 \%$ of the respondents were a non-governmental employee and the remaining $11 \%$ were a government employee. From the above discussions, it can be understood that a greater part of the respondents had good levels of education which might serve as important input in promoting the participation of the community in formulating and implementing the tourism policy in their localities. Besides, most of the respondents $(74 \%)$ have lived in the city since birth. This may be an indicator that majority of the respondents are assumed to have sufficient knowledge and experience about the city.

\subsection{Local Community Policy Awareness}

This part of the paper discusses issues related with first objective of study: to understand the awareness of the community about the policy and their roles. In order to assess their level of awareness, the respondents were asked seven questions in relation to their awareness of local community roles stated in the tourism development policy using five-point scales format. The results are presented in Table 3 . In relation to the general question of having awareness about the role of the local community in implementing the respective policy. Hence, 58.1\%, $38.2 \%$ and $3.7 \%$ of the respondents rated their response with strong agreement, agreement and not sure about their awareness respectively. The result indicates that about $96.3 \%$ of the respondents have some level of awareness about the role of local community in the efforts of policy implementation. This can serve as fertile ground to promote the participation of the local community in formulating policies and strategies to realize mission and objectives of the policy in the regional state. 
Table 3: Local Community Awareness about Tourism Policy Implementation roles

\begin{tabular}{|c|c|c|c|c|c|c|c|}
\hline \multirow[b]{2}{*}{ No } & \multirow[b]{2}{*}{ Roles } & \multicolumn{5}{|l|}{ Response } & \multirow{2}{*}{$\begin{array}{l}\text { Total } \\
\%\end{array}$} \\
\hline & & SA (\%) & $\mathbf{A}(\%)$ & NS (\%) & D (\%) & SD (\%) & \\
\hline 1 & $\begin{array}{l}\text { Protect resources with a sense of } \\
\text { ownership and collaboration }\end{array}$ & $87(45.5)$ & $84(44)$ & $10(5.2)$ & $6(3.2)$ & $4(2.1)$ & 100 \\
\hline 2 & $\begin{array}{llll}\begin{array}{l}\text { Participate in } \\
\text { development }\end{array} & \text { tourist } & \text { site } \\
\end{array}$ & $72(37.7)$ & $95(49.7)$ & $22(11.6)$ & $2(1)$ & - & 100 \\
\hline 3 & Ensure local peace and security & $76(39.8)$ & $87(45.6)$ & $21(11)$ & $5(2.6)$ & $\begin{array}{l}2 \\
1\end{array}$ & 100 \\
\hline 4 & $\begin{array}{l}\text { Protect socio-cultural values and } \\
\text { natural environment }\end{array}$ & $72(34)$ & $95(49.7)$ & $13(6.8)$ & $16(8.5)$ & $2(1)$ & 100 \\
\hline 5 & $\begin{array}{l}\text { Participate in benefit sharing } \\
\text { activities }\end{array}$ & $131(68.6)$ & $53(27.7)$ & $4(2.2)$ & $2(1)$ & $1(0.5)$ & 100 \\
\hline 6 & $\begin{array}{l}\text { Provide good care and hospitality } \\
\text { the tourist in line with local custom }\end{array}$ & $76(43.4)$ & $83(39.8)$ & $32(16.8)$ & - & $\begin{array}{l}- \\
- \\
\end{array}$ & 100 \\
\hline 7 & $\begin{array}{l}\text { Provide adequate quantity and } \\
\text { quality goods and service }\end{array}$ & $68(35.6)$ & $83(43.5)$ & $36(18.8)$ & $3(1.6)$ & $1(0.5)$ & 100 \\
\hline
\end{tabular}

Note: $\mathrm{SA}=$ strongly agree, $\mathrm{A}=$ agree, $\mathrm{NS}=$ not sure, $\mathrm{D}=$ disagree, $\mathrm{SD}=$ strongly disagree

Source: Field Survey

The result in table 3 shows about respondents' knowledge about the role of local community in implementing the national policy in their locality. Accordingly, $89.5 \%$ of respondents indicate that they have awareness about their roles and responsibilities in protecting local resources with a sense of ownership and collaboration. Besides, $87.4 \%$ of the respondents showed their agreement on community awareness about the participation of the community in developing tourist attraction sites and products. Almost majority of respondents responded positively on their awareness about ensuring peace and security in the locality, protection of local socio-cultural values and natural environment, participation in benefit sharing, providing care and hospitality to tourists and providing good quantity and quality goods and service. Generally, it can be learned from the above table that majority of the respondents have good level of awareness about their role in policy implementation. The above finding was consistent with the information provided by tourism experts as stated:

Even though the locals are not formally aware of their role in the policy implementation, they informally have good awareness about their role because of their long and close existence in tourist destination area or tourism sector in the city in general.

\subsection{Local Community Role in Tourism Development Policy Implementation}

This part is concerned with second research objective; to investigate local community role for the implementation of tourism development policy. As stated in national Tourism Development Policy, local communities are expected to play different roles which are important in facilitating the implementation endeavor become effective (MoCT, 2009). In line with this, the sampled respondents were asked to rate the level of local community members' participation role in decision-making, training and benefit sharing.

Table 4: Local Community Areas of Participation

\begin{tabular}{|l|l|c|c|c|c|c|c|}
\hline \multirow{2}{*}{ No } & \multirow{2}{*}{ Areas of Participation } & \multicolumn{5}{|c|}{ Reponses } & Total \\
\cline { 3 - 7 } & SA(\%) & A(\%) & NS (\%) & D(\%) & SD (\%) & \% \\
\hline 1 & Decision-making & $80(41.9)$ & $90(47.2)$ & $17(8.9)$ & $2(1)$ & $2(1)$ & 100 \\
\hline 2 & Trainings & $91(47.6)$ & $83(43.5)$ & $13(6.8)$ & $1(0.5)$ & $3(1.6)$ & 100 \\
\hline 3 & Benefit-sharing activities & $63(33)$ & $98(51.3)$ & $29(15.2)$ & $1(0.5)$ & - & 100 \\
\hline
\end{tabular}

\section{Source: Field Survey}

Note: $\mathrm{SA}=$ strongly agree, $\mathrm{A}=$ agree, $\mathrm{NS}=$ not sure, $\mathrm{D}=$ disagree, $\mathrm{SD}=$ strongly disagree

As shown in table $4,84.8 \%$ to $91.1 \%$ of the sampled respondents indicated their agreement and strong agreement in relation to the participation of local community in the three areas of policy engagement. Hence, it can be learned from the findings, majority of local peoples have been participating in decision making, training, and tourism benefit-sharing activities. These results are also supported by the data collected through observation and interview that show there are practical training given for the local community in Enya Abida handcraft center and technical training for various stakeholders (hotel operators, tourist guides and museum owners). Community participation in decision-making process was facilitated by the regional implementing agency by providing the chance for the community to participate in consultative seminars and workshop. However, the benefit accrued from the sector was limited campared to the potentails of the regionla state. The services and accommodations facilities are not of the expected and standard quality in satisfying the tourist's demands and expectations. 
In addition, table 6 presents the mean score of the respondents about their level of involvement and participation. The result implies that local people were playing faire role in implementing the policy in the region. The survey result is also supported by the information gathered through interview and observation. The information obtained from the interview conducted with government shows that the participation of the community was limited. Mainly the role of the community was observed by converting their homes in to guest houses with budgetary support of the municipality. Besides, the community involves by handing over heritages to museums and in selling artifacts to tourists. The observation result also shows that local are playing their role by protecting their heritages through doing preservation work to their traditional house, participating in benefit sharing activities like hyena feeding, hotels, and souvenir shops.

Table 5: The Extent of Local Participation

\begin{tabular}{|l|l|l|l|}
\hline No & Extent of participation & Frequency & Percentage \\
\hline 1 & Local people are taking the leading role & 1 & 0.5 \\
\hline 2 & $\begin{array}{l}\text { Local people have their voice in the decision-making process of local } \\
\text { tourism development }\end{array}$ & 49 & 25.7 \\
\hline 3 & $\begin{array}{l}\text { Local people are consulted when tourism policies are being made and } \\
\text { implemented }\end{array}$ & 3 & 1.6 \\
\hline 4 & $\begin{array}{l}\text { Local people are consulted during decision making but the final decision on } \\
\text { tourism development are made by government bodies }\end{array}$ & 131 & 68.6 \\
\hline 5 & Local people are not participating to play their role by any mean & 7 & 3.6 \\
\hline \multicolumn{2}{|l|}{ Total } & 191 & 100 \\
\hline
\end{tabular}

\section{Source: Field Survey}

The tourism development policy although was designed to pave the way for local community engagement, the response from the majority respondents looks disappointing. As indicated in the above table, $68.6 \%$ of the respondents believed that the decision is made by government bodies with limited consultation of local community. From this it can be learned that the participation of local community in the policy formulation and implementation in their locality is limited since the ultimate decisions are made by bureaucracy and politicians. Besides, the above finding seems consistent with the response of the interviews conducted with the City Tourism Bureau Head. The head said that the bureau is annually conducting seminars or meetings with concerned stakeholders in parallel with the celebration of international tourism day. Accordingly, attempts were also made to organize different events by the bureau to consult the community, diaspora and stakeholders. Particularly, the bureau gives an attention to the July 4 celebration where the diaspora Harari Community customarily come collectively to visit their family every five years.

Table 6: Independence in Level of Local Community Participation in Policy Implementation across all Three Clusters

\begin{tabular}{lccc}
\hline Clusters & Mean & $\begin{array}{c}\text { Levene test of variance } \\
\text { p-value }\end{array}$ & $\begin{array}{c}\text { Kruskal Wallis Test } \\
\text { p-value }\end{array}$ \\
\hline Cluster 1(keb1,7) & 3.18 & & .091 \\
Cluster 2(keb 5,6) & 3.34 & .0005 & \\
Cluster 3(keb 2,3,4) & 3.22 & & \\
$\quad$ Total & 2.94 & & \\
\hline
\end{tabular}

\section{Source: Field Survey}

The above tables 6 presents measures of statistical independence in the average response on level of local community participation in tourism policy implementation across all three clusters. The homogeneity of variance test result indicates sig value of 0.005 which is equal to a p-value of 0.005 . So, the variance in the level of local community participation in policy implementation across three clusters is statistically significant. Moreover, the Kruskal Wallis Test for independence on the average level of local community participation in playing their role in tourism policy implementation across three clusters indicates sig value of 0.091 which is $p>0.005$. So, the average levels of local community participation across all three clusters have no statistically significant difference. This result implies that the average level of local community participation in playing their role in policy implementation is similar or fair all across three clusters or tourism destination area of "Jugol".

\subsection{Factors Affecting Local Community Participation}

The part is concerned with research objective three; which is to identify factors affecting local community participation in playing their role in the tourism policy implementation. In general, in order to identify what factors are affecting local community participation in tourism policy implementation, respondents from the local people or households were asked to rate their levels of agreement or not with the five factors (see table below) using a five-point scale. 
Table 7: Factors Affecting Local Community Participation

\begin{tabular}{|c|c|c|c|c|c|c|c|}
\hline \multirow[b]{2}{*}{ No } & \multirow[b]{2}{*}{ Factors } & \multicolumn{5}{|l|}{ Response } & \multirow[b]{2}{*}{ Total $\%$} \\
\hline & & SA (\%) & A (\%) & NS (\%) & $\mathrm{D}(\%)$ & SD (\%) & \\
\hline 1 & Participatory Public Administration & $80(41.9)$ & $59(30.9)$ & $19(9.9)$ & $18(9.4)$ & $15(7.9)$ & 100 \\
\hline 2 & Coordination and Cooperation & $70(36.6)$ & $71(37.2)$ & $19(9.9)$ & $16(8.4)$ & $15(7.9)$ & 100 \\
\hline 3 & Community Awareness & $77(40.3)$ & $69(36.1)$ & $13(6.8)$ & $18(9.4)$ & $14(7.3)$ & 100 \\
\hline 4 & Community Participation Approach & $88(46.1)$ & $81(42.4)$ & $8(4.2)$ & $4(4.2)$ & $10(5.2)$ & 100 \\
\hline 5 & Community Capacity & $71(37.2)$ & $93(48.7)$ & $26(13.6)$ & $1(0.5)$ & - & 100 \\
\hline
\end{tabular}

Note: $\mathrm{SA}=$ strongly agree, $\mathrm{A}=$ agree, $\mathrm{NS}=$ not sure, $\mathrm{D}=$ disagree, $\mathrm{SD}=$ strongly disagree

Source: Field Survey

The result in table 7 above shows different factors which are affecting local people participation in implementing the respective policy. Consequently, $72.8 \%$ and $88.5 \%$ the respondents expressed their agreement with respect to participatory public administration and community participation approach in institutions respectively. Additionally, $76.4 \%$ and $73.8 \%$ respondents believed that community awareness and coordination and cooperation have an effect on policy implementation. Even if the above result shows all five factors identified are affecting local community participation in policy implementation, but all factors don't have statistically significant relation with local community participation in tourism policy implementation. As it can be learned from table 8 , the correlation test indicates that all the factors with the exception of community capacity have significant positive correlation with local community participation in the process of implementing the respective policy. This might be associated with those who are participating in the process are not of the more educated residents who are assumed to have the knowledge and skill that serve as input to effectively implement the policy.

Table 8: Spearman Rank Correlations

\begin{tabular}{|c|c|c|c|}
\hline \multirow[t]{2}{*}{ No } & \multirow[t]{2}{*}{ Factors } & \multicolumn{2}{|c|}{$\begin{array}{c}\text { Level of Local Community Participation in } \\
\text { Tourism Policy Implementation } \\
\text { Spearman }\end{array}$} \\
\hline & & $\mathbf{r}_{\mathrm{s}}$ & Sig. (2 tailed) \\
\hline 1 & Participatory Public Administration & $0.472 * *$ & 0.000 \\
\hline 2 & Coordination and Cooperation & $0.499 * *$ & 0.000 \\
\hline 3 & Community Awareness & $0.448^{* *}$ & 0.000 \\
\hline 4 & Community Participation Approach & $0.275^{* *}$ & 0.000 \\
\hline 5 & Community Capacity & -0.093 & 0.199 \\
\hline
\end{tabular}

Source: Field Survey

\subsection{Challenges of the Tourism Policy Implementation}

Tourism policy implementation is not an easy task. Implementation might encounter various challenges that need attention and actions from regional policy makers and implementers. The findings of the study indicate that Harari regional state has limited experience in contextualize the national policy with the regional environment. Although the federal constitution proves a mandated to regional governments to contextualize the national policy, the attempted by the regional government to formulate its own policy is almost not existent. In a nutshell, tourism policy implementation has faced four main challenges in the region:

- Lack of awareness among the community, stakeholders and even the tourism office

- Limited coordination and cooperation among the stakeholders and community

- Lack of trained and professional manpower especially in the hospitality sector

- Shortage of finance and budgeting

\section{Conclusion and Policy Implication}

It is well noted that community participation and engagement is an important input in successfully implementing public policies and programs. Ethiopia Tourism Development Policy is one of the national policies which gives due attention to community participation as one of its basic policy formulation and implementation principles. In line with this, based on the findings of the study, it can be concluded about efforts in Harari Peoples Regional State in implementing the national tourism in relation to local community involvement that:

1. Local community members have good awareness about their roles in implementing the national and regional tourism development policy and strategies. This may be associated with the greater experience and exposure of residents with tourist for many years.

2. The community play an important role in the implementation process of the policy. The role was manifested by participating in training, decision-making process and benefit sharing activity. 
3. Local community participation in the regions was affected by participatory public administration, community awareness, coordination/cooperation and approaches of participation.

From the above conclusive remarks, it can be learned that there are different issues which need an attention at regional and national level. Strengthening the existing community participation in the tourism sector is important duty and responsibility to the executive branch of the government. Besides, it is of urgency to address the shortage of trained and professional workforce to ripe the benefits of the policy at local and regional level.

\section{REFERENCES}

Baum, T., \& Weinz, W. (2010). Developments and challenges in the hospitality and tourism sector: issues paper for discussion at the Global Dialogue Forum for the Hotels, Catering, and Tourism Sector. Retrieved December19/2017 from http://www.ilo.org/

Bule, M. (2016). Community Involvement and Participation in Tourism Development in Harar City, Ethiopian Civil Service University, Addis Ababa, Ethiopia.

Essays, UK. (2013). Ancient and Historical Town Of Harar Tourism Essay. Retrieved December 19/2017 from https://www.ukessays.com/essays/tourism/ancient-and-historical-town-of-harar-tourism-essay.php?vref=1

Federal Democratic Republic of Ethiopia Population Census Commission. (2008). Summary and Statistical report of the 2007 population and housing census. Addis Ababa, Ethiopia.

FDRE (1995). Constitution, Addis Ababa, Ethiopia

Getahun, M. (2011). The Impact of Service Trade on Economic Growth of Ethiopia: The case of tourism, Addis Ababa University, Addis Ababa, Ethiopia.

Harari Culture, Heritage \&Tourism Bureau (2002-2008EC). Tourist Statistics, Harar, Harari Region.

Harari Culture, Heritage and Tourism Bureau (2015/16). Annual report, Harar, Harari Region.

Harari People Regional State (2016). Harari People's Regional Directory, Harar, Harari region. Retrieved Dec19/2017

Haymanot (2017). Ethiopian Tourism Development Policy (2009) and its Implementation: Critical Evaluation Using PCI Method, Journal of culture and tourism, vol.1, pp222-239.

Messele, W. (2010). Community participation in tourism development in Tigray: The case of Axum (Doctoral dissertation, Mekelle University). Retrieved December 23/2017 from https://opendocs.ids.ac.uk

Ministry of Culture \& Tourism (2009). Ethiopian Tourism Development Policy. Addis Ababa, Ethiopia: FDRE Government.

Ministry of Culture \& Tourism (2012). Ethiopia's Tourism Sector: Strategic Paths to Competitiveness and Job Creation.

Tafesse, A. (2016). The Historic Route in Ethiopia Tourism Development, University of Gondar, Gondar, Ethiopia, African Journal of Hospitality, Tourism, and Leisure, Vol 5(2). Retrieved Nov19/2017 from http://www.ajhtl.com

World Travel \& Tourism Council (2017). Travel \& Tourism Economic Impact; World, London, United Kingdom. Retrieved December 17/2017 from https://www.wttc.org

World Travel \& Tourism Council (2017). Travel \& Tourism Economic Impact; Ethiopia, London, United Kingdom. Dec 19/2017 Retrieved Dec 19/2017 from https://www.wttc.org

Zaei, M. E., \& Zaei, M. E. (2013). The impacts of the tourism industry on the host community. European journal of tourism hospitality and research, 1(2), 12-21., Vol.1, Issue.2, pp.12-21. Retrieved November 20/2017 from http://www.eajournal.org 